Jacobien J. Hoogerwerf

Michael W. T. Tanck

Marieke A. D. van Zoelen

Xavier Wittebole

Pierre-François Laterre

Tom van der Poll

\section{Soluble ST2 plasma concentrations predict mortality in severe sepsis}

Received: 28 August 2008

Accepted: 3 November 2009

Published online: 12 February 2010

(c) The Author(s) 2010. This article is published with open access at

Springerlink.com

J. J. Hoogerwerf - M. A. D. van Zoelen .

T. van der Poll

Center for Infection and Immunity

Amsterdam (CINIMA),

University of Amsterdam,

Amsterdam, The Netherlands

J. J. Hoogerwerf $(\bowtie) \cdot$ M. A. D. van Zoelen •

T. van der Poll

Center of Experimental and Molecular

Medicine, University of Amsterdam,

Meibergdreef 9, Room G2-132,

1105 AZ Amsterdam, The Netherlands

e-mail: j.j.hoogerwerf@amc.uva.nl

Tel.: +31-20-5669111

Fax: +31-20-6977192

M. W. T. Tanck

Department of Clinical Epidemiology,

Biostatistics and Bioinformatics, Academic

Medical Center, University of Amsterdam,

Amsterdam, The Netherlands
X. Wittebole · P.-F. Laterre Department of Intensive Care and Emergency Medicine, St. Luc University Hospital, UCL, Brussels, Belgium

Abstract Purpose: Patients with sepsis-after surviving the initial hyperinflammatory phase-display features consistent with immunosuppression, including

hyporesponsiveness of immunocompetent cells to bacterial agents.

Immunosuppression is thought to be facilitated by negative regulators of toll-like receptors, including membrane-bound ST2. We investigated the release of soluble ST2 (sST2), a decoy receptor that inhibits membrane-bound ST2 signaling, during sepsis. Methods: The study population comprised 95 patients with severe sepsis admitted to one of two intensive care units (ICUs) at the day the diagnosis of severe sepsis was made. Blood was obtained daily from admission (day 0) until day 7 and finally at day 14 . Twenty-four healthy subjects served as controls. sST2 and cytokines were measured in serum. Results: Mortality among patients was $34 \%$ in the ICU and $45 \%$ in the hospital. On admission, sepsis patients had higher sST2 levels $[10,989(7,871-15,342) \mathrm{pg} / \mathrm{ml}$, geometric mean $(95 \%$ confidence interval, CI)] than controls [55 (20145) $\mathrm{pg} / \mathrm{ml}, P<0.0001]$. Serum sST2 remained elevated in patients from day 0 to 14 and correlated with disease severity scores $(P<0.001)$ and cytokine levels on day 0 and during course of disease $(P<0.0001)$. Nonsurvivors displayed elevated SST2 levels compared with survivors of the intensive care unit $(P<0.0001)$. Conclusions: Sepsis results in sustained elevation of serum SST2 levels, which correlates with disease severity and mortality.

Keywords ST2 - Sepsis - Innate immune response $\cdot$ Cytokines

\section{Introduction}

Sepsis is a major health problem which afflicts approximately 750,000 patients in the USA each year, associated with mortality rates of $20-50 \%$ [1]. In the past decade it has become clear that patients with severe sepsis-after an initial hyperinflammatory phase-become immunosuppressed. Indeed, patients with sepsis display features consistent with immunosuppression, including loss of delayed hypersensitivity, inability to clear infection, and predisposition to nosocomial infections. Clear evidence of immunosuppression in sepsis comes from studies showing hyporesponsiveness of immunocompetent cells to bacterial agents [2-5]. Toll-like receptors (TLRs) are essential for early detection of pathogens [6,7], but can cause excessive inflammation when their signaling activity remains uncontrolled. To avoid detrimental inflammatory responses TLR signaling is regulated by-among other 
mechanisms-TLR inhibitors, such as MyD88 short, interleukin-1 receptor-associated kinase-M, and ST2, which have been suggested to play an important role during the immunosuppressive state in severe sepsis [8$10]$.

The $s t 2$ gene produces a soluble secreted form (sST2) and a transmembrane form (ST2L) and is expressed in several cells, including Th2 cells [11], mast cells [12], and macrophages [13]. ST2L serves an important negative regulatory function for TLR signaling, as illustrated by the fact that mice lacking ST2L are unable to develop endotoxin tolerance [10]. Recently it has become clear that interleukin (IL)-33 can bind to ST2L, thereby triggering Th2-associated responses [14]. Soluble ST2, which is mainly secreted by fibroblasts [15], has been suggested to act as a decoy receptor by binding IL-33, thereby inhibiting signaling by ST2L $[16,17]$. Previously it has been shown that soluble ST2 concentrations are elevated in sera of patients with various immune disorders and patients suffering from myocardial infarction [18-23]. The functional role of soluble ST2 in vivo has not been fully elucidated. Mouse studies have revealed that administration of a recombinant soluble ST2-Fc fusion protein or a soluble ST2 vector reduces inflammation and lethality in hepatic and intestinal ischemia/reperfusion injury $[24,25]$ and attenuates inflammatory responses in allergic lung inflammation [26, 27].

Considering that ST2 possibly contributes to the regulation of the immune response during severe inflammation, we hypothesized that soluble ST2 levels would be elevated in patients with sepsis and possibly correlate with disease outcome. Therefore, we here performed an explorative study to determine the extent of soluble ST2 release over time in patients with severe sepsis and its correlation with disease severity and mortality.

\section{Materials and methods}

Patients and design

This study was approved by the scientific and ethics committees of the St. Luc University Hospital (Brussels, Belgium) and the St. Pierre's Hospital (Ottignies, Belgium). Written informed consent was obtained from all subjects or their relatives. The study population comprised 95 patients with severe sepsis, defined as a known or suspected infection plus a systemic inflammatory response syndrome, and failure of at least one organ [28]; these patients were admitted to the intensive care unit (ICU) of either St. Luc University Hospital $(n=59)$ or St. Pierre's Hospital $(n=36)$ at the day severe sepsis was diagnosed, and blood in a dry tube was obtained each day starting at inclusion (day 0) until day 7 and finally at day 14. After centrifugation, serum was then stored at $-70^{\circ} \mathrm{C}$ until analysis. In the ICUs of both hospitals sepsis was treated according to the surviving sepsis guidelines [29]; as such no major treatment differences existed between the two ICUs. A subgroup of this study population was used previously to describe the release of high mobility group box 1 in sepsis patients $(n=51)$ [30]. A total of 24 healthy subjects, consisting of a combination of healthy elderly from a nearby old people's home and healthy colleagues from the laboratory, served as controls.

\section{Measurements and assays}

Data were collected prospectively from patient records, patient data management system (at the ICU), and hospital information system. The following variables were collected when appropriate: date of birth/death, sex, acute physiology and chronic health evaluation (APACHE) II and sepsis-related organ failure assessment (SOFA) scores, organ dysfunction (both defined according to the 1992 American College of Chest Physicians/Society of Critical Care Medicine Consensus Conference [31]), length of intensive care and hospital stay, blood culture results, culture results of focus of infection, date of death, body temperature, and level of C-reactive protein (CRP). Analysis of serum samples was performed after patient recruitment had been completed. Soluble ST2 was measured by commercially available enzyme-linked immunosorbent assay (ELISA; R\&D Systems, Minneapolis, MN; detection limit $780 \mathrm{pg} / \mathrm{ml}$ ) according to the instructions of the manufacturer. Tumor necrosis factor (TNF)- $\alpha$, IL-1 $\beta$, IL-6, IL-8, IL-10, and IL-12p70 were determined using a cytometric beads array multiplex assay (BD Biosciences, San Jose, CA) according to the instructions of the manufacturer. Detection limit was $2.5 \mathrm{pg} / \mathrm{mL}$ for all six cytokines measured.

\section{Statistical analysis}

Continuous patient characteristics were tested for normal distribution using the Shapiro-Wilk test $(W>0.90)$ and are presented as mean \pm standard deviation or median with 25 th and 75 th percentile where appropriate. Categorical variables are presented as number and percentage. Soluble ST2 and cytokine levels were right-skewed, and log-transformed to obtain a normal distribution. These variables are presented as geometric mean with $95 \%$ confidence interval $(95 \% \mathrm{CI})$. Correlations between different variables are expressed as Pearson or Spearman correlation coefficients, where appropriate. Values for patients at different time points and baseline values in the control group were compared using the independent $t$ test (with correction for unequal variances, if necessary). 
Differences between sepsis groups and between survivors and nonsurvivors of ICU or hospital stay were analyzed using a linear mixed model with rank-transformed soluble ST2 and cytokine values because of unequal variances at the different time points. In case of an overall significant difference, post hoc tests were performed at the individual time points. All these analyses were carried out by using SPSS (version 14; SPSS, Chicago, IL). To account for multiple testing, $P$ values $<0.001$ were considered statistically significant.

\section{Results}

Sepsis results in elevated serum soluble ST2 levels irrespective of source of infection

The demographic and clinical characteristics of patients with severe sepsis and healthy controls are presented in Table 1. In total, 95 patients were included, with mortality of $34 \%$ in the ICU and overall in-hospital mortality of $45 \%$. The primary sources of infection were the lung [in 49 patients, 52\%; communityacquired pneumonia (CAP)], the abdomen (in 24 patients, 25\%; peritonitis), and the urinary tract (in 19 patients, 20\%; UTI). Compared with 24 healthy controls (66 \pm 22 years, mean $\pm \mathrm{SD}$; 50\% male), septic patients $(66 \pm 14$ years, mean $\pm \mathrm{SD} ; 57 \%$ male $)$ displayed elevated circulating levels of soluble ST2 starting on day 0 with a peak at day 1 . Thereafter soluble ST2 concentrations decreased again, but were not yet normalized on day 14 compared with controls (Fig. 1a). No statistical difference in increase of soluble ST2 was seen when patients were stratified by sepsis due to pneumonia, peritonitis, or urinary tract infection (Fig. 1b, c, d).
Soluble ST2 levels correlate with disease severity on day of onset

Soluble ST2 levels in serum were significantly correlated with both APACHE II and SOFA scores on day of onset (day 0; Table 2). Moreover, soluble ST2 levels correlated with presence of a positive blood culture. Body temperature and C-reactive protein measured on day of onset did not correlate with soluble ST2 levels. Additionally, soluble ST2 levels did not correlate with length of ICU stay.

Elevation of soluble ST2 levels in nonsurviving septic patients

Soluble ST2 levels were higher in patients who died in the ICU $(n=32)$ than in patients who left the ICU alive $(n=63)$; this difference between ICU survivors and nonsurvivors was sustained until day 14 (Fig. 2a). In this analysis we compared ICU survivors and nonsurvivors since cause of death in patients who died in the hospital after ICU discharge was mostly unrelated to sepsis. Although soluble ST2 levels between overall hospital survivors $(n=52)$ and overall nonsurvivors $(n=43)$ were significantly different (Fig. 2b), it appeared that soluble ST2 levels of patients who died in the hospital after ICU discharge $(n=11)$ were lower than those of patients who died in the ICU $(n=32)$ (Fig. 2c).

Soluble ST2 levels correlate with cytokine levels in serum of septic patients

To investigate whether soluble ST2 levels are correlated with circulating cytokine levels in patients with severe sepsis, we measured the serum concentrations of TNF- $\alpha$, IL-6, IL-8, IL-10, and IL-12p70 (Table 3). TNF- $\alpha$, IL-1 $\beta$,

Table 1 Patient characteristics

\begin{tabular}{|c|c|c|c|c|c|c|}
\hline Characteristics & $\begin{array}{l}\text { Patients with } \\
\text { severe sepsis } \\
\text { (all) }(n=95)\end{array}$ & $\begin{array}{l}\text { Patients with sepsis } \\
\text { due to peritonitis } \\
{[n=24(25)]}\end{array}$ & $\begin{array}{l}\text { Patients with sepsis } \\
\text { due to pneumonia } \\
{[n=49(52)]}\end{array}$ & $\begin{array}{l}\text { Patients with sepsis } \\
\text { due to UTI } \\
{[n=19(20)]}\end{array}$ & $\begin{array}{l}\text { Patients with } \\
\text { sepsis due to } \\
\text { other }[n=3(3)]\end{array}$ & $\begin{array}{l}\text { Control } \\
\text { population } \\
(n=24)\end{array}$ \\
\hline Age (years) & $66 \pm 14$ & $59 \pm 15$ & $68 \pm 13$ & $71 \pm 10$ & $60 \pm 24$ & $66 \pm 22$ \\
\hline Male sex & $60(57)$ & $17(71)$ & $32(65)$ & $11(58)$ & $0(0)$ & $12(50)$ \\
\hline APACHE II & $27 \pm 9$ & $28 \pm 10$ & $25 \pm 8$ & $29 \pm 8$ & $29 \pm 15$ & NA \\
\hline SOFA score & $10 \pm 5$ & $11 \pm 4$ & $9 \pm 5$ & $11 \pm 5$ & $13 \pm 7$ & NA \\
\hline ICU stay (days) & $10(5-22)$ & $15(6-29)$ & $10(5-21)$ & $7(2-22)$ & $6(4-6)$ & NA \\
\hline Pos. blood culture & $45(47)$ & $13(54)$ & $17(35)$ & $14(74)$ & $1(33)$ & NA \\
\hline $\begin{array}{l}\text { Pos. culture of } \\
\text { infectious focus }\end{array}$ & $81(85)$ & $20(83)$ & $40(82)$ & 19 (100) & $2(67)$ & NA \\
\hline Mortality ICU & $32(34)$ & $9(38)$ & $16(33)$ & $6(32)$ & $1(33)$ & NA \\
\hline Mortality overall & $43(45)$ & $12(50)$ & $23(47)$ & 7 (37) & $1(33)$ & NA \\
\hline
\end{tabular}

UTI urinary tract infection, APACHE acute physiology and chronic Data are mean $\pm \mathrm{SD}$, median (25-75\% interquartile range) or no. health evaluation, SOFA sepsis-related organ failure assessment, (\%) when appropriate $I C U$ intensive care unit, NA not applicable 

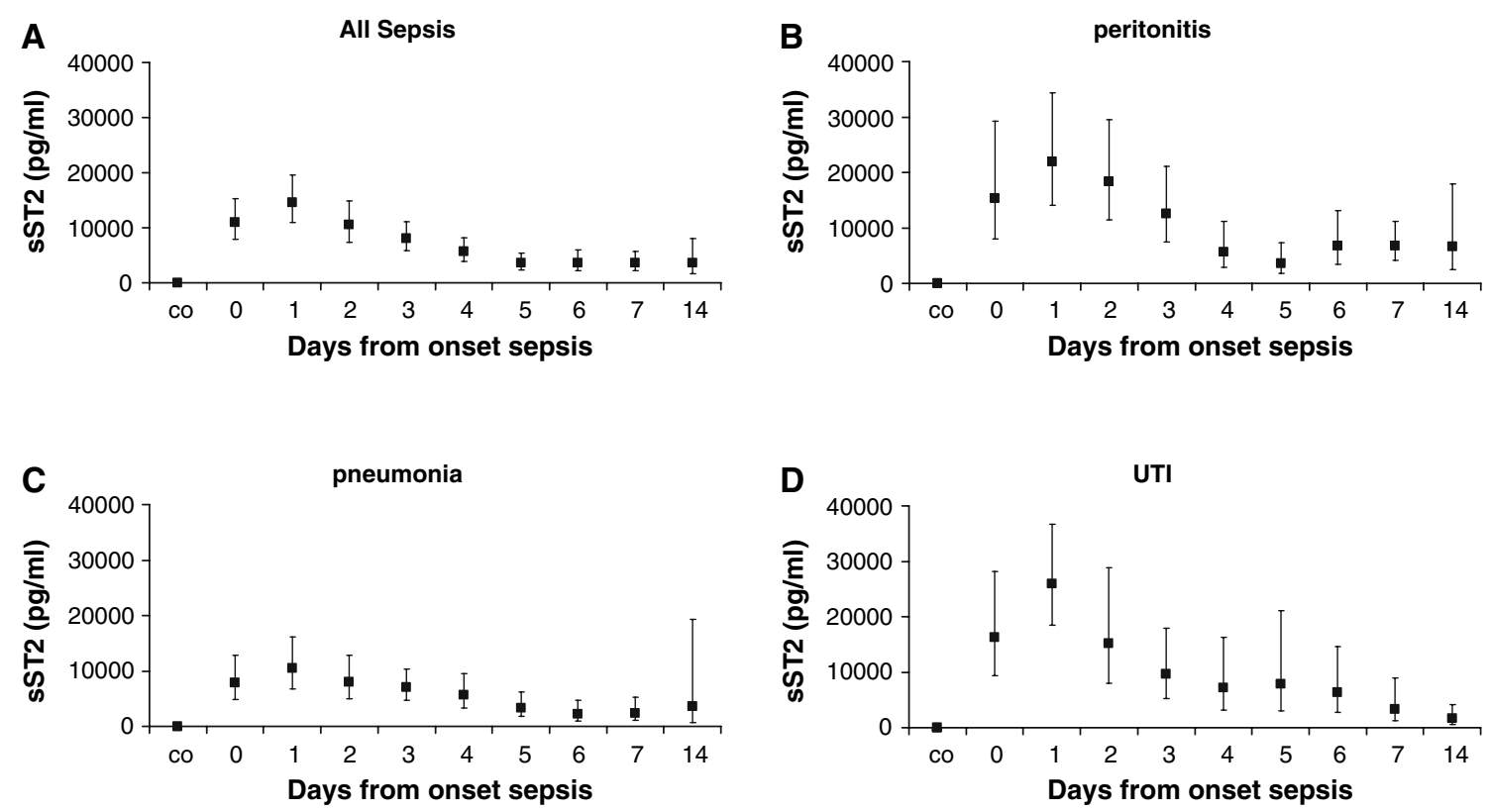

Fig. 1 Soluble ST2 levels in serum of patients with severe sepsis. Concentrations of soluble ST2 were measured in serum of patients with severe sepsis ("all sepsis," a, $n=95$ ) and subgroups of these patients with different infectious sources: abdomen $(\mathbf{b}, n=24)$, lungs $(\mathbf{c}, n=49)$, or urinary tract $(\mathbf{d}, n=19)$, and from healthy

and IL-12p70 levels were either very low or undetectable in patients and not significantly different from in healthy controls (data not shown). Serum IL-6, IL-8, and IL-10 concentrations were elevated in sepsis patients at all time points compared with controls (Table 3). Soluble ST2 levels and levels of cytokines IL-6, IL-8, and IL-10 were significantly correlated at day of onset (Table 4). During the course of disease this correlation became less strong (Table 4). Since correlation between soluble ST2 and cytokine levels became less strong during the course of disease than on day of onset (Table 4), we were interested in investigating cytokine levels in ICU survivors versus nonsurvivors (Fig. 3). Although overall IL-6, IL-8, and IL-10 levels were higher in patients who died in the ICU,

Table 2 Correlation between soluble ST2 and clinical markers on day of onset

\begin{tabular}{lcc}
\hline Clinical markers & \multicolumn{2}{c}{ Serum soluble ST2 } \\
\cline { 2 - 3 } & $r$ & $P$ value \\
\hline APACHE II & 0.45 & 0.0001 \\
SOFA score & 0.49 & $<0.0001$ \\
Pos. blood culture & 0.45 & 0.001 \\
Serum level CRP & 0.12 & 0.41 \\
ICU stay (days) & -0.07 & 0.62 \\
Body temperature & 0.12 & 0.42 \\
\hline
\end{tabular}

APACHE acute physiology and chronic health evaluation, SOFA sepsis-related organ failure assessment controls $(n=24)$. Data are geometric means with $95 \%$ confidence intervals. At each time point, sepsis patients had higher soluble ST2 levels than healthy controls $(P<0.0001)$ (for reasons of clarity not indicated in the figure)

the differences between survivors and nonsurvivors were only apparent during the first several days after admission.

\section{Discussion}

In light of the possible contribution of negative regulators of TLRs to the immunosuppressed state in septic patients, we were interested in investigating the extent of soluble ST2 release over time in patients with severe sepsis. Our findings demonstrate that sepsis results in sustained and stable elevation of soluble ST2, irrespective of the source of infection. Moreover, soluble ST2 levels correlate with disease severity and mortality.

Previously, others have demonstrated elevated soluble ST2 levels in serum of patients with various immune disorders such as asthma, pulmonary fibrosis, various autoimmune diseases, and dengue virus infection [18-20, 32]. In addition, soluble ST2 levels have been described to be elevated in patients with sepsis [21]. However, this study, showing soluble ST2 serum levels at only one time point ( $<48 \mathrm{~h}$ from time of diagnosis), was performed in a limited number of patients $(n=15)$, which may explain the failure to demonstrate correlations between soluble ST2 and disease severity or mortality. The current study extends these findings, not only by showing elevation of soluble ST2 in a much larger population of septic patients 

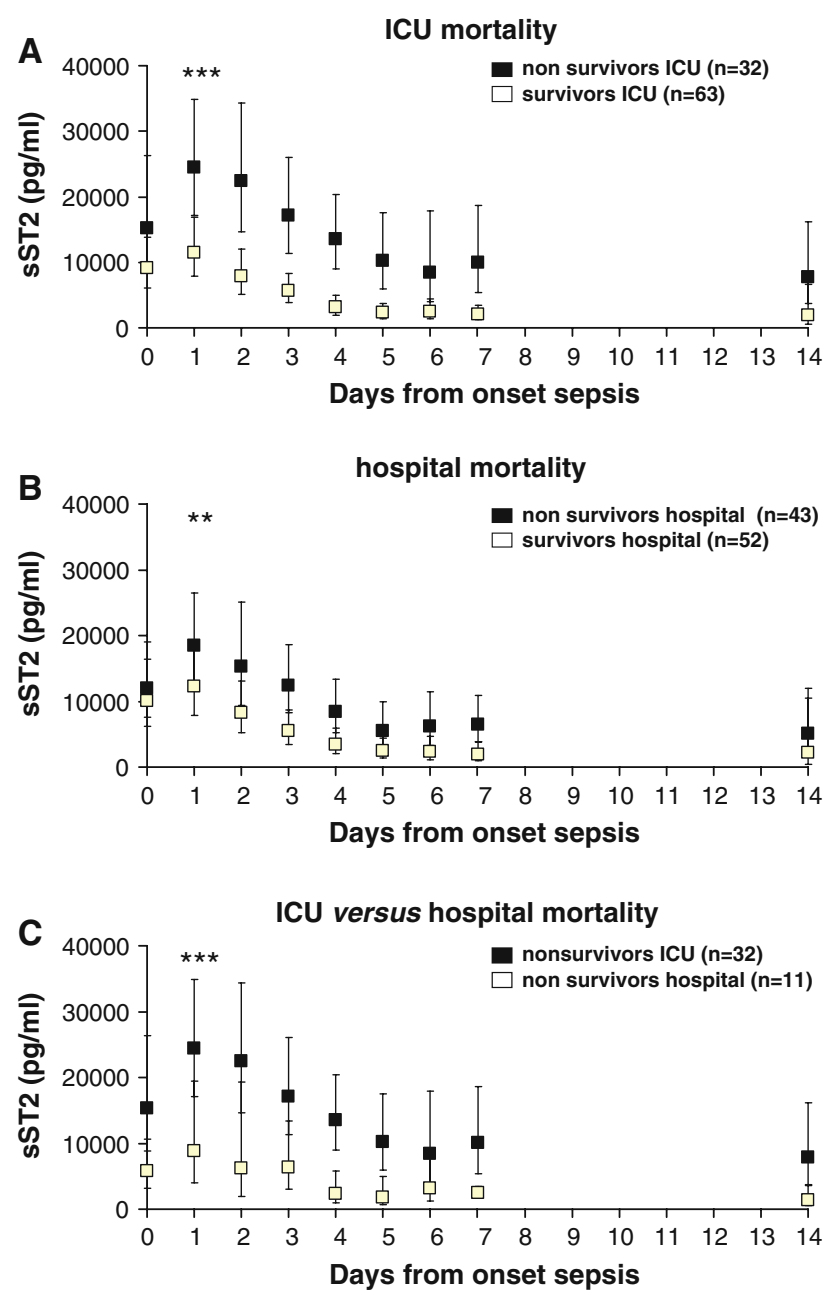

Fig. 2 Elevated soluble ST2 levels correlate with mortality. Soluble ST2 levels in patients who left the ICU alive $(n=63$; open squares) versus patients who died in the ICU ( $n=32$; filled squares) (a), in patients who left the hospital alive ( $n=52$; open squares) versus patients who died in the hospital ( $n=43$; filled squares) (b), and in patients who died in the ICU $(n=32$; filled squares) versus patients who died in the hospital after ICU discharge ( $n=11$; open squares) (c). Data are geometric means with $95 \%$ confidence intervals. $* * P<0.001, * * * P<0.0005$

stratified according to infection source, but also by providing information on soluble ST2 levels during the course of sepsis and correlations with concurrently measured cytokine concentrations. Of note, the first blood sample was obtained on the day of ICU admission, which was also the day the diagnosis of "severe sepsis" was made. This does not exclude, however, that severe sepsis was already present prior to admission, although given the severity of this syndrome, it seems unlikely that this would have occurred in many patients and/or for prolonged time periods. A second limitation of this study could be that patients were recruited from two ICUs, although both centers followed the surviving sepsis guidelines [29].
Table 3 Cytokine levels in patients with severe sepsis

\begin{tabular}{llll}
\hline Day & IL-6 & IL-8 & IL-10 \\
\hline 0 & $351[211-584]$ & $214[125-364]$ & $23[13-40]$ \\
1 & $341[220-529]$ & $184[121-279]$ & $19[12-28]$ \\
2 & $154[104-229]$ & $100[71-143]$ & $12[8-16]$ \\
3 & $131[79-217]$ & $99[66-148]$ & $14[10-20]$ \\
4 & $134[87-207]$ & $106[73-155]$ & $15[10-21]$ \\
5 & $75[53-106]$ & $84[61-116]$ & $9[7-11]$ \\
6 & $66[41-105]$ & $102[68-153]$ & $9[7-12]$ \\
7 & $66[45-96]$ & $86[63-118]$ & $10[8-13]$ \\
14 & $85[48-151]$ & $91[52-158]$ & $7[5-10]$ \\
Control & $4[3-7]$ & $13[10-17]$ & $2[1-2]$ \\
\hline
\end{tabular}

Data are geometric means $[95 \% \mathrm{CI}]$ in $\mathrm{pg} / \mathrm{ml} ; P<0,0001$ (using independent $t$ test) for all time points for all cytokines, when compared with controls

Table 4 Correlations between soluble ST2 and cytokine levels in patients with severe sepsis

\begin{tabular}{llrlll}
\hline & \multicolumn{2}{l}{ Soluble ST2 } & & \\
\cline { 2 - 3 } & \multicolumn{2}{l}{ Day 0 } & & \multicolumn{2}{l}{ Day 0-14 } \\
\cline { 2 - 3 } \cline { 5 - 6 } & $r$ & $P$ value & & $r$ & $P$ value \\
\hline IL-6 & 0.39 & 0.006 & & 0.48 & $<0.0001$ \\
IL-8 & 0.55 & $<0.0001$ & & 0.51 & $<0.0001$ \\
IL-10 & 0.48 & 0.0007 & & 0.48 & $<0.0001$ \\
\hline
\end{tabular}

Values measured at day 0 and during the complete stay at the ICU $P$ values from linear mixed models

Our finding that soluble ST2 serum levels were most upregulated at day 1 from onset of disease is in line with previous studies describing soluble ST2 levels during the course of disease. Recently, patients infected with dengue virus were found to have mildly elevated levels of soluble ST2 with a peak on day 0 (day of onset) and day 1 [32]; however, soluble ST2 levels returned to normal within 2 weeks. Moreover, studies describing soluble ST2 levels in patients suffering from myocardial infarction revealed that soluble ST2 was upregulated at day 1, but returned to normal levels after 3 days [22, 23, 33]. In contrast, our results indicate that, relative to controls, soluble ST2 remained upregulated until 14 days after onset of sepsis. In this respect it is interesting to note that release of soluble ST2 in the circulation after myocardial infarction is thought to result from mechanical stress on cardiomyocytes [22]. Considering that soluble ST2 is produced by fibroblasts underneath the vascular endothelium, it is tempting to speculate that soluble ST2 is only released into the circulation upon disruption of the endothelial layer, in which case soluble ST2 would be indicative of the extent of tissue injury. This would also provide an explanation for the difference in duration of elevated soluble ST2 levels in various inflammatory processes. Additional research is warranted to further investigate the exact source of soluble ST2 during sepsis and other inflammatory diseases. In 

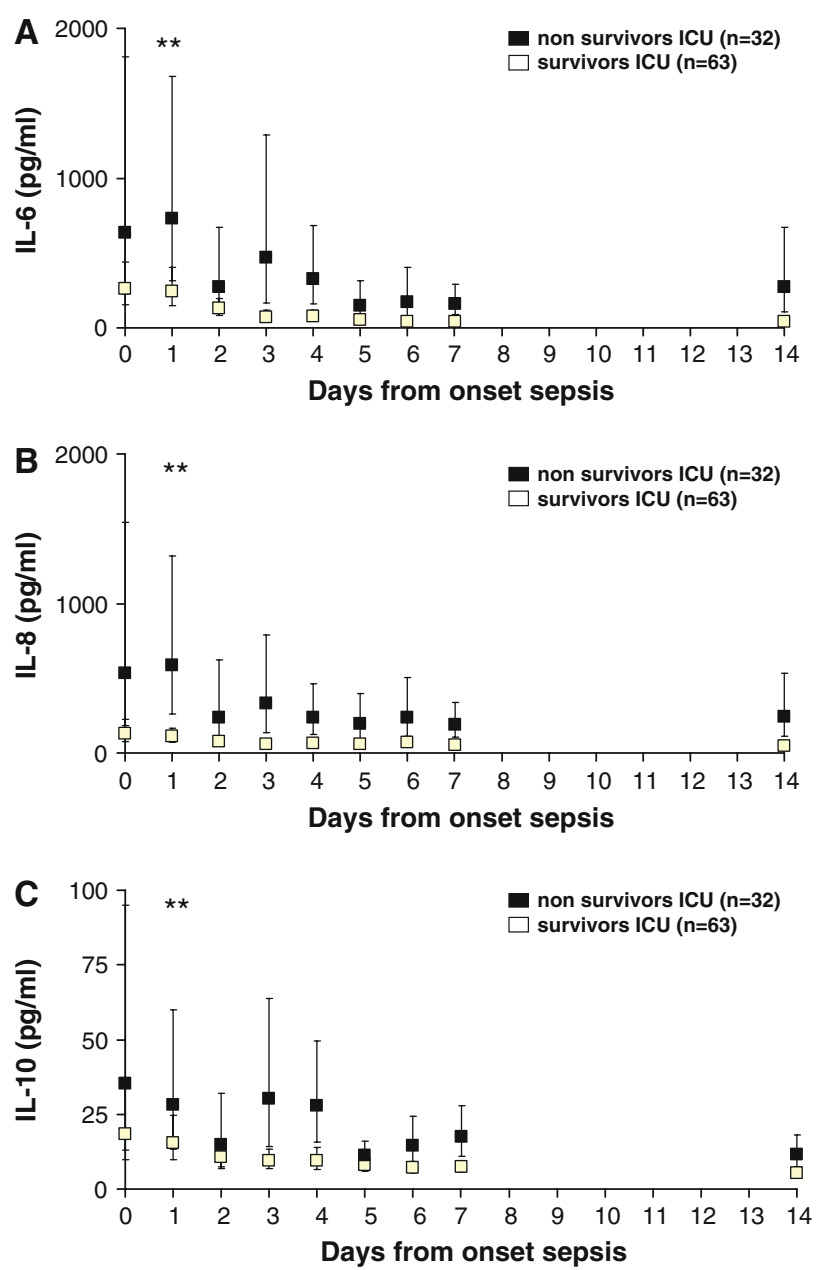

Fig. 3 Cytokine levels in patients with severe sepsis. IL-6 (a), IL-8 (b), and IL-10 (c) levels were measured in serum of patients with severe sepsis, stratified into patients who did not survive their ICU admission ( $n=32$; filled squares) versus patients who survived their ICU stay ( $n=63$; open squares). Data are geometric means with $95 \%$ confidence intervals. $* * P<0.0005$

addition, considering the association between ST2 and dampening of the immune response [8], it would be of considerable interest to examine a possible relationship between soluble ST2 levels and the occurrence of secondary nosocomial infections.

Various studies have demonstrated associations between risk of death and cytokine levels during sepsis [34-39]. However, cytokines have a short circulating half-life and their release primarily occurs early after exposure to an infectious challenge. Moreover, the range of cytokine levels from survivors and nonsurvivors often overlap, making them of poor prognostic value [1]. Considering the abundant literature on the possible value of circulating cytokines as prognostic indicators in sepsis we wanted to compare our soluble ST2 data with concurrently measured cytokine concentrations. Although there were significant differences in cytokine levels (IL-6, IL-8, and IL-10) between survivors and nonsurvivors in the current investigation, cytokine levels were especially widely spread in nonsurvivors and tended to decrease sharply after 5 days. In contrast, soluble ST2 levels of nonsurvivors remained stably elevated until day 14 compared with survivors. This difference in course during sepsis is further corroborated by the fact that correlations between soluble ST2 levels and cytokine levels became less strong during the course of disease when compared with their correlations on the day of onset. Notably, serum TNF- $\alpha$ and IL- $1 \beta$ levels were low or undetectable in the current cohort of sepsis patients. Previous studies have reported highly variable circulating levels of these two proinflammatory cytokines, at least in part depending on the assays used and the severity of sepsis [39]. Our present data fit into this extensive literature in that many earlier studies have reported low TNF- $\alpha$ and IL- $1 \beta$ concentrations in the circulation of sepsis patients, which is in accordance with the short circulating half-life of these mediators [39].

\section{Conclusions}

We here establish that severe sepsis results in stable and sustained elevation of serum soluble ST2 levels. Moreover, soluble ST2 levels correlate with disease severity and mortality. Further investigations are warranted to elucidate the function of soluble ST2 during the immune response in septic patients.

\section{Conflict of interest None.}

Open Access This article is distributed under the terms of the Creative Commons Attribution Noncommercial License which permits any noncommercial use, distribution, and reproduction in any medium, provided the original author(s) and source are credited.

\section{References}

1. Angus DC, Wax RS (2001) Epidemiology of sepsis: an update. Crit Care Med 29:S109-S116
2. Hotchkiss RS, Karl IE (2003) The pathophysiology and treatment of sepsis. N Engl J Med 348:138-150
3. Hotchkiss RS, Nicholson DW (2006) Apoptosis and caspases regulate death and inflammation in sepsis. Nat Rev Immunol 6:813-822 
4. van der Poll T, Opal SM (2008) Hostpathogen interactions in sepsis. Lancet Infect Dis 8:32-43

5. Volk HD, Reinke P, Docke WD (2000) Clinical aspects: from systemic inflammation to 'immunoparalysis'. Chem Immunol 74:162-177

6. Akira S, Uematsu S, Takeuchi O (2006) Pathogen recognition and innate immunity. Cell 124:783-801

7. Beutler B, Jiang Z, Georgel P, Crozat K, Croker B, Rutschmann S, Du X, Hoebe K (2006) Genetic analysis of host resistance: toll-like receptor signaling and immunity at large. Annu Rev Immunol 24:353-389

8. Liew FY, Xu D, Brint EK, O'Neill LA (2005) Negative regulation of toll-like receptor-mediated immune responses. Nat Rev Immunol 5:446-458

9. Deng JC, Cheng G, Newstead MW, Zeng X, Kobayashi K, Flavell RA, Standiford TJ (2006) Sepsis-induced suppression of lung innate immunity is mediated by IRAK-M. J Clin Invest 116:2532-2542

10. Brint EK, Xu D, Liu H, Dunne A, McKenzie AN, O'Neill LA, Liew FY (2004) ST2 is an inhibitor of interleukin 1 receptor and toll-like receptor 4 signaling and maintains endotoxin tolerance. Nat Immunol 5:373-379

11. Xu D, Chan WL, Leung BP, Huang F, Wheeler R, Piedrafita D, Robinson JH, Liew FY (1998) Selective expression of a stable cell surface molecule on type 2 but not type 1 helper T cells. J Exp Med 187:787-794

12. Moritz DR, Rodewald HR, Gheyselinck J, Klemenz R (1998) The IL-1 receptorrelated $\mathrm{T} 1$ antigen is expressed on immature and mature mast cells and on fetal blood mast cell progenitors. J Immunol 161:4866-4874

13. Oshikawa K, Yanagisawa K, Tominaga S, Sugiyama Y (2002) ST2 protein induced by inflammatory stimuli can modulate acute lung inflammation. Biochem Biophys Res Commun 299:18-24

14. Schmitz J, Owyang A, Oldham E, Song Y, Murphy E, McClanahan TK, Zurawski G, Moshrefi M, Qin J, Li X, Gorman DM, Bazan JF, Kastelein RA (2005) IL-33, an interleukin-1-like cytokine that signals via the IL-1 receptor-related protein ST2 and induces $\mathrm{T}$ helper type 2-associated cytokines. Immunity 23:479-490

15. Bergers G, Reikerstorfer A, Braselmann S, Graninger P, Busslinger M (1994) Alternative promoter usage of the Fosresponsive gene Fit-1 generates mRNA isoforms coding for either secreted or membrane-bound proteins related to the IL-1 receptor. EMBO J 13:1176-1188
16. Hayakawa H, Hayakawa M, Kume A, Tominaga S (2007) Soluble ST2 blocks interleukin-33 signaling in allergic airway inflammation. J Biol Chem 282:26369-26380

17. Sanada S, Hakuno D, Higgins LJ, Schreiter ER, McKenzie AN, Lee RT (2007) IL-33 and ST2 comprise a critical biomechanically induced and cardioprotective signaling system. J Clin Invest 117:1538-1549

18. Oshikawa K, Kuroiwa K, Tago K, Iwahana H, Yanagisawa K, Ohno S, Tominaga SI, Sugiyama Y (2001) Elevated soluble ST2 protein levels in sera of patients with asthma with an acute exacerbation. Am J Respir Crit Care Med 164:277-281

19. Tajima S, Oshikawa K, Tominaga S, Sugiyama Y (2003) The increase in serum soluble ST2 protein upon acute exacerbation of idiopathic pulmonary fibrosis. Chest 124:1206-1214

20. Kuroiwa K, Arai T, Okazaki H, Minota S, Tominaga S (2001) Identification of human ST2 protein in the sera of patients with autoimmune diseases. Biochem Biophys Res Commun 284:1104-1108

21. Brunner M, Krenn C, Roth G, Moser B, Dworschak M, Jensen-Jarolim E, Spittler A, Sautner T, Bonaros N, Wolner E, Boltz-Nitulescu G, Ankersmit HJ (2004) Increased levels of soluble ST2 protein and IgG1 production in patients with sepsis and trauma. Intensive Care Med 30:14681473

22. Weinberg EO, Shimpo M, De Keulenaer GW, MacGillivray C, Tominaga S, Solomon SD, Rouleau JL, Lee RT (2002) Expression and regulation of ST2, an interleukin-1 receptor family member, in cardiomyocytes and myocardial infarction. Circulation 106:2961-2966

23. Shimpo M, Morrow DA, Weinberg EO, Sabatine MS, Murphy SA, Antman EM, Lee RT (2004) Serum levels of the interleukin-1 receptor family member ST2 predict mortality and clinical outcome in acute myocardial infarction. Circulation 109:2186-2190

24. Yin H, Huang BJ, Yang H, Huang YF, Xiong P, Zheng F, Chen XP, Chen YF, Gong FL (2006) Pretreatment with soluble ST2 reduces warm hepatic ischemia/reperfusion injury. Biochem Biophys Res Commun 351:940-946

25. Fagundes CT, Amaral FA, Souza AL, Vieira AT, Xu D, Liew FY, Souza DG, Teixeira MM (2007) ST2, an IL-1R family member, attenuates inflammation and lethality after intestinal ischemia and reperfusion. J Leukoc Biol 81:492-499
26. Lohning M, Stroehmann A, Coyle AJ, Grogan JL, Lin S, Gutierrez-Ramos JC, Levinson D, Radbruch A, Kamradt T (1998) T1/ST2 is preferentially expressed on murine Th2 cells, independent of interleukin 4, interleukin 5, and interleukin 10, and important for Th2 effector function. Proc Natl Acad Sci USA 95:6930-6935

27. Oshikawa K, Yanagisawa K, Tominaga S, Sugiyama Y (2002) Expression and function of the ST2 gene in a murine model of allergic airway inflammation. Clin Exp Allergy 32:1520-1526

28. Levy MM, Fink MP, Marshall JC, Abraham E, Angus D, Cook D, Cohen J, Opal SM, Vincent JL, Ramsay G (2003) 2001 SCCM/ESICM/ACCP/ ATS/SIS international sepsis definitions conference. Crit Care Med 31:12501256

29. Dellinger RP, Carlet JM, Gerlach H, Ramsey G, Levy M (2004) The surviving sepsis guidelines: not another "groundhog day". Crit Care Med 32:1601-1602

30. van Zoelen MA, Laterre PF, van Veen SQ, van Till JW, Wittebole X, Bresser P, Tanck MW, Dugernier T, Ishizaka A, Boermeester MA, van der Poll T (2007) Systemic and local high mobility group box 1 concentrations during severe infection. Crit Care Med 35:2799-2804

31. (1992) American College of Chest Physicians/Society of Critical Care Medicine Consensus Conference: definitions for sepsis and organ failure and guidelines for the use of innovative therapies in sepsis. Crit Care Med 20:864-874

32. Becerra A, Warke RV, de Bosch N, Rothman AL, Bosch I (2008) Elevated levels of soluble ST2 protein in dengue virus infected patients. Cytokine 41:114-120

33. Weinberg EO, Shimpo M, Hurwitz S, Tominaga S, Rouleau JL, Lee RT (2003) Identification of serum soluble ST2 receptor as a novel heart failure biomarker. Circulation 107:721-726

34. Calandra T, Gerain J, Heumann D, Baumgartner JD, Glauser MP (1991) High circulating levels of interleukin-6 in patients with septic shock: evolution during sepsis, prognostic value, and interplay with other cytokines. The Swiss-Dutch J5 immunoglobulin study group. Am J Med 91:23-29

35. Casey LC, Balk RA, Bone RC (1993) Plasma cytokine and endotoxin levels correlate with survival in patients with the sepsis syndrome. Ann Intern Med 119:771-778

36. Damas P, Reuter A, Gysen P, Demonty J, Lamy M, Franchimont P (1989) Tumor necrosis factor and interleukin-1 serum levels during severe sepsis in humans. Crit Care Med 17:975-978 
37. Marks JD, Marks CB, Luce JM, Montgomery AB, Turner J, Metz CA, Murray JF (1990) Plasma tumor necrosis factor in patients with septic shock. Mortality rate, incidence of adult respiratory distress syndrome, and effects of methylprednisolone administration. Am Rev Respir Dis 141:94-97
38. Pinsky MR, Vincent JL, Deviere J, Alegre M, Kahn RJ, Dupont E (1993) Serum cytokine levels in human septic shock. Relation to multiple-system organ failure and mortality. Chest 103:565-575
39. Hack CE, Aarden LA, Thijs LG (1997) Role of cytokines in sepsis. Adv Immunol 66:101-195 